\title{
A comparative study of the effect of gaur gum and gum arabic on snacks products chakli and sev
}

\author{
Nikhil Solanke and Pradip Pawar
}

\begin{abstract}
Hydrocolloids such as gaur gum and gum arabic are used for reducing the content of oil from the fried food item. The results shows that the fat replaces add into food product show the positive effect on product and body, health risks were no longer challenged. The present study was conducted to develop deep fat fried snacks, which is based on gaur gum and gum arabic which are acts as fat replacer but the addition of the fat replacer have the limitation if there is large amount of addition of the fat replacer may affect the food product textural properties and overall acceptability of the product by consumer. Experimental design with varying the gaur gum (0.2 to $1.0 \%)$ and gum arabic (0.3 to $1.5 \%)$ as independent variables produced 13 different combinations that were studied using response surface methodology to investigate the effect of these variables on product responses. The comparative study evaluated the effect of gaur gum and gum arabic on physical properties of snacks product chakli, as the addition of gaur gum and gum arabic in different ranges in sev and chakli product and prepared the snacks product. The comparative study was done on physical parameters like oil absorption index and oil uptake ratio. Increasing the gaur gum and gum arabic content in sev and chakli sample there is decreases the oil absorption index and oil uptake ratio. Overall data suggested that positive effect of both the hydrocolloids on snacks samples.
\end{abstract}

Key Words : Chakli, Gum arabic, Gaur gum, Oil absorption index, Oil uptake ratio, Sev

How to cite this article : Solanke, Nikhil and Pawar, Pradip (2020). A comparative study of the effect of gaur gum and gum arabic on snacks products chakli and sev. Food Sci. Res. J., 11(1): 28-33, DOI : 10.15740/HAS/FSRJ/11.1/28-33.Copyright@ 2020: Hind Agri-Horticultural Society.

\footnotetext{
Author for correspondence :

Nikhil Solanke, Department of Food Science and Technology, Shri. Jagdish Pradesh Jhabarmal Tibrewala University, Jhunjhunu (Rajasthan) India

Email: nikhilsolanke15@gmail.com

Associate Authors' :

Pradip Pawar, Department of Chemical Technology, Sant Gadge Baba Amravati University, Amravati (M.S.) India

Email: papawar40@rediffmail.com
} 